\title{
Stakeholder Engagement for
}

\section{Applying Research to Policy} and Practice for Health (ARCH)

Authors: Wema Mtika, Helena Wilcox, Nicole Feune De Colombi

09 April 2021 | The Global Health Network

https://doi.org/10.48060/tghn.6 


\section{트르르르 THE GLOBAL HEALTH NETWORK}

\section{Abstract}

For research uptake to be effective, there is need to involve relevant individuals, groups, organisations, and institutions. Stakeholder mapping enables one to identify these groups, as well their importance in research uptake, and how to engage with them. In this document, we highlight steps of stakeholder mapping in research uptake, as adapted from literature. 


\section{트르를 THE GLOBAL HEALTH NETWORK}

Effective research uptake requires that the relevant people and organisations be invited and involved in the project in some way.

A key activity to inform who these groups are and how to engage with them is a stakeholder mapping exercise. This helps to understand who these groups are, why they might be interested, how important their involvement is, and how to engage with them in a way that can contribute to successful research uptake.

Reed et al. (2009) defines 'stakeholder mapping', often used interchangeably with 'stakeholder analysis', as "a process that (1) defines aspects of a social and natural phenomenon affected by a decision or action; (2) identifies individuals, groups and organisations who are affected by or can affect those parts of the phenomenon; and (3) prioritises these individuals and groups for involvement in a decision-making process"(1).

The Applying Research to Policy and Practice for Health (ARCH) programme recently started a stakeholder mapping process, and this series of information and resources shares our experience to help others.

\section{Why do stakeholder mapping?}

There are many reasons it may be important to do a stakeholder mapping and analysis. These include:

- To build a common understanding on significant stakeholders within the research uptake landscape and who may impact on programme success.

- To categorise stakeholders according to their (potential) role in the project and to determine methods of engagement

- To assess acceptability of the project

- To set a plan for engaging with stakeholders throughout the project

- To account for potential risks to the project and consider appropriate mitigation strategies

\section{What questions does stakeholder mapping help answer?}

- Who will be affected?

- When should various stakeholders be engaged across the project?

- What are the spatial impacts of the project?

- Who has the power to influence the outcome?

- Who are the potential allies and opponents?

- What coalitions might build around this issue?

- Are there people whose voices or interests in the issue may not be heard?

- Who will be responsible for managing the outcome?

- Who can facilitate or impede the outcome through their participation, nonparticipation, or opposition?

- Who can contribute financial or technical resources? (2) 


\section{Steps for stakeholder mapping}

The stakeholder mapping process varies from project to project and as such there is no one standard methodology in literature. Various authors in varying health areas and spatial contexts such as regional and national have reported different flexible stakeholder mapping methodologies. As such, the ARCH programme adapted and developed a stakeholder mapping methodology based on different steps of methodologies in literature.

The steps are as follows:

1. Defining the initial context and scope of the project and stakeholder mapping. Defining the initial scope means understanding what is in scope/out of scope for your stakeholder mapping. This could include the types of organisations, the focus of disease area, and the locations of individuals and organisations as well as the scale they work at (for example national/regional/global).

\section{Preliminary identification and categorisation of stakeholders}

This step involves identifying stakeholders that are involved in research uptake as observed in literature (2-9), such as research papers, conference presentations, reports, grants, media digests and other verbal or written accounts of major events (3).

Stakeholders may also be categorised according to anticipated stakeholder categories in literature $(2,9)$. These categories include researchers, academia, policy makers, policy networks, health professionals, funding institutions, media, etc. Stakeholders are also categorised according to their level of operation, such as national or international, and other emerging categories relevant to the project (7).

An initial analysis or screening of the importance of the stakeholder's input in the mapping exercise is done and this informs the next stage, i.e., who to involve in the stakeholder mapping workshop. The influential stakeholders are selected on the basis of having multiple appearances in searches or other outputs, suggesting they are information rich $(3,6)$. These would be stakeholders that have a lot of links with other stakeholders with links and stakeholders that are not linked (could easily be missed) (10).

\section{Stakeholder mapping workshop}

A virtual stakeholder mapping workshop is held with representatives of the initial stakeholder groups $(2,4,6,10)$, including partners as agreed by programme partners. In preparation for the workshop, it may be useful to include a pre-workshop exercise in which each participant considers the research uptake landscape and stakeholders in their context. If the programme is global or large scale, and the workshop is virtual, it may be feasible to hold separate workshops in each region or country.

The workshop may take the following workflow:

- introduce the programme and stakeholder mapping activity to participants

- understand what research uptake means to participants

- brainstorm and identify more stakeholders and their categories (snowballing) to produce a comprehensive list of stakeholders 


\section{E=E=- THE GLOBAL HEALTH NETWORK}

- refine the stakeholder mapping scope i.e., which stakeholder groups to involve? why? where?

- understand the roles of different stakeholders in relation to research uptake

- understand how different types of stakeholders are perceived

- understand the levels of power and interest stakeholders have regarding research uptake

- understand stakeholder relationships and how they work together

\section{Stakeholder analysis}

Workshop participants analyse stakeholders they mention according to their power or influence and interest in the project. A common approach to this analysis is the 'Mendelow's Power (influence)-Interest (importance) Matrix' (7); placing the stakeholders in the matrix they most likely belong to, in order to give a visual representation of their positionality in the project, while noting the reasoning behind that characterisation. The "power" or "level of influence" denotes the degree to which a stakeholder can impact the project and/or its outcomes, while "interest" denotes how much a stakeholder cares about the project outcomes (11).

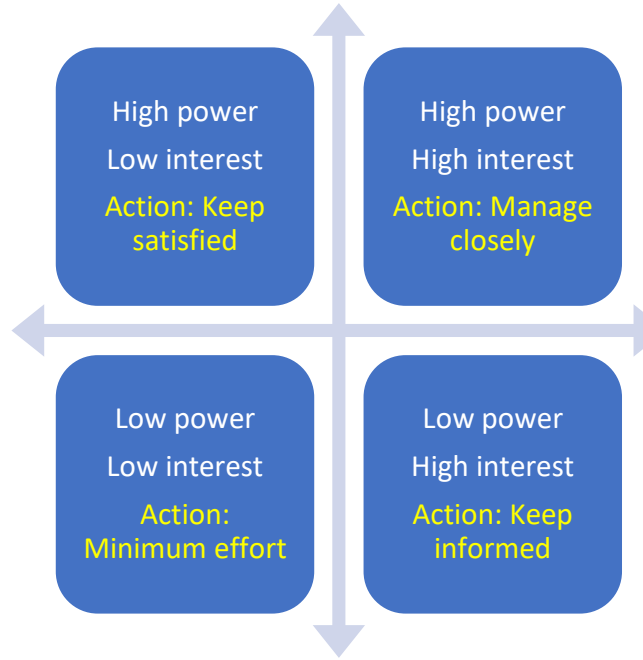

As GroupMap (2020) suggests, the extent of engaging with the stakeholders will depend on which group they fall in;

- High power/influence and high interest: these are "key players" and are considered a high priority to be fully engaged in the project

- High power/influence and low interest: these are "context settlers" and should still be kept satisfied, but not to a great extent

- Low power and high interest: these are "subjects" and may point out areas of improvement. They may become influential by collaborating with other influential stakeholders

- Low power and low interest: these are the "crowd", and there is little need for consideration and engagement. A constant check on their levels of power and interest should constantly be checked nevertheless, in case it changes (11) 


\section{트르르르 THE GLOBAL HEALTH NETWORK}

For virtual workshops, virtual-group-writing boards such as Miro (https://miro.com/) may work well as close as flip charts for in person meetings, in facilitating this exercise. Additionally, a google form containing similar stakeholder mapping questions as with the workshop can be shared to participants that are unable to attend the workshop. This information can then be used to supplement workshop data.

\section{Analysing workshop data}

The workshop data can be analysed using a thematic content analysis approach (12), having transcribed audio or video recordings. In this approach, 'codes' or 'tags' are attached to the data based on meaning of concepts within the data and any similar codes are ultimately collapsed into themes. If several workshops were held, the themes from all discussions would then be combined and interpreted.

An output to this exercise is a framework depicted in the following table. The table shows how stakeholders may already be involved (or not) with the programme and consider the most appropriate engagement routes. This also considers the stakeholder groups $(4,7,9)$. The further step would be to develop this into a full stakeholder engagement plan.

\begin{tabular}{|c|c|c|c|c|c|c|c|}
\hline $\begin{array}{l}\text { Stakeholder } \\
\text { group }\end{array}$ & $\begin{array}{l}\text { Stakeholder } \\
\text { name/ } \\
\text { organisation }\end{array}$ & $\begin{array}{l}\text { Governance } \\
\text { level } \\
\text { (country, } \\
\text { region/ } \\
\text { international }\end{array}$ & $\begin{array}{l}\text { Key } \\
\text { interest } \\
\text { (topic/ } \\
\text { health } \\
\text { area) }\end{array}$ & $\begin{array}{l}\text { Power/ } \\
\text { influenc } \\
\text { e (L, M, } \\
\text { H) }\end{array}$ & Why? & $\begin{array}{l}\text { Interest } \\
(L, M, H)\end{array}$ & $\begin{array}{l}\text { How can } \\
\text { they } \\
\text { contribute/ } \\
\text { get } \\
\text { involved? }\end{array}$ \\
\hline & & & & & & & \\
\hline
\end{tabular}




\section{References}

1. Reed MS, Graves A, Dandy N, Posthumus H, Hubacek K, Morris J, et al. Who's in and why? A typology of stakeholder analysis methods for natural resource management. J Environ Manage [Internet]. 2009 Apr [cited 2020 Nov 15];90(5):193349. Available from: https://abdn.pure.elsevier.com/en/publications/whos-in-and-why-atypology-of-stakeholder-analysis-methods-for-na

2. Reed MS, Curzon R. Stakeholder mapping for the governance of biosecurity: a literature review. J Integr Environ Sci [Internet]. 2015 Jan 2 [cited 2020 Oct 16];12(1):15-38. Available from: http://www.tandfonline.com/doi/abs/10.1080/1943815X.2014.975723

3. Petruney T, Harlan S V., Lanham M, Robinson ET. Increasing Support for Contraception as HIV Prevention: Stakeholder Mapping to Identify Influential Individuals and Their Perceptions. Shea BJ, editor. PLoS One [Internet]. 2010 May 24 [cited 2020 Oct 23];5(5):e10781. Available from: https://dx.plos.org/10.1371/journal.pone.0010781

4. Makan A, Fekadu A, Murhar V, Luitel N, Kathree T, Ssebunya J, et al. Stakeholder analysis of the Programme for Improving Mental health carE (PRIME): Baseline findings. Int J Ment Health Syst [Internet]. 2015 Jul 8 [cited 2020 Oct 23];9(1):1-12. Available from: https://link.springer.com/articles/10.1186/s13033-015-0020-z

5. Slabá M. Stakeholder profile and stakeholder mapping of SMEs. Littera Scr [Internet]. 2016 [cited 2020 Oct 22]; Available from: http://journals.vstecb.cz/category/litterascripta/9-rocnik/1_2016/

6. Puri S, Fernandez S, Puranik A, Anand D, Gaidhane A, Quazi Syed Z, et al. Policy content and stakeholder network analysis for infant and young child feeding in India. BMC Public Health [Internet]. 2017 Jun 13 [cited 2020 Nov 9];17(S2):461. Available from: http://bmcpublichealth.biomedcentral.com/articles/10.1186/s12889-017-4339-z

7. Ginige K, Amaratunga D, Haigh R. Mapping stakeholders associated with societal challenges: A Methodological Framework. In: Procedia Engineering. Elsevier Ltd; 2018. p. 1195-202.

8. Katz R, Graeden E, Abe K, Attal-Juncqua A, Boyce MR, Eaneff S. Mapping stakeholders and policies in response to deliberate biological events. Heliyon [Internet]. 2018 Dec 1 [cited 2020 Nov 6];4(12):e01091. Available from: /pmc/articles/PMC6310771/?report=abstract

9. Khan SB. Translation of the shortened dental arch research into clinical practice: a stakeholder mapping approach. BDJ Open [Internet]. 2020 Dec 1 [cited 2020 Nov 13];6(1). Available from: /pmc/articles/PMC7387451/?report=abstract

10. CARIAA, ASSAR. Stakeholder and influence network mapping exercise with the government, development and research actors in Namibia [Internet]. 2015 [cited 2020 Nov 13]. Available from: http://www.uct.ac.za/

11. GroupMap. Stakeholder Analysis, Stakeholder Mapping Template - GroupMap [Internet]. 2020 [cited 2020 Nov 9]. Available from: https://www.groupmap.com/maptemplates/stakeholder-analysis/

12. O.Nyumba T, Wilson K, Derrick CJ, Mukherjee N. The use of focus group discussion methodology: Insights from two decades of application in conservation. Methods Ecol Evol [Internet]. 2018 Jan 1 [cited 2020 Jul 16];9(1):20-32. Available from: https://besjournals.onlinelibrary.wiley.com/doi/full/10.1111/2041-210X.12860 